\title{
Case Study: Developing Computational Thinking Skill During Pandemic Situation
}

\author{
${ }^{1}$ Mharta Adji Wardana \& ${ }^{2}$ Iwan Pranoto \\ ${ }^{1}$ Institut Teknologi Bandung, Bandung, Indonesia \\ ${ }^{2}$ Institut Teknologi Bandung, Bandung, Indonesia \\ ${ }^{1}$ mhartawardana@gmail.com \\ 2 iwanpranoto@ymail.com
}

\begin{abstract}
In 1980, Seymour Papert mentioned that computational thinking is the idea where the interaction between a student and computer can become a mental model, assisting the learning process. This idea becomes well known as constructionism. Thus, Papert believes that the computer presence or even the thinking of computer interaction may help the student to think and learn better. It is more general than the present widely accepted perception of computational thinking, where it focuses on the utilization of computers in problem-solving only. This case study aims to describe how students can learn computational thinking through the traditional curriculum and unplugged setting in this pandemic. Three middle school students participated in a concrete mathematics lesson design in a middle school lesson on linear function topic. The result indicates that clear instructions and gradual examples will help students understand the series of operations that are part of computational thinking.
\end{abstract}

Keywords: computational thinking, lesson design, linear function, mathematics content, mental model.

\section{Introduction}

This study recalls the existing definitions of computational thinking (CT) proposed by previous researchers. Cansu and Cansu (2019) lists and examines various definitions of CT from 2009 to 2014. Some researchers also stated that CT is about formulating problems and creating solutions that a computer can apply effectively (Wing, 2006; Yadav et al., 2014; Denning, 2009; Hemmedinger, 2010).

There are various existing definitions of computational thinking proposed by previous researchers. Cansu and Cansu (2019) lists those definitions that emphasize CT's utilization as a problem-solving tool. We try to evaluate those definitions by examining Papert's original idea about constructionism theory as follows.

Table 1

Some Definitions of CT

\begin{tabular}{lll}
\hline Source & Definition & Evaluation \\
\hline Wing (2014) & $\begin{array}{l}\text { Computational thinking is the thought } \\
\text { processes used to formulate a problem } \\
\text { and express its solution or solutions in } \\
\text { terms a computer can apply effectively. }\end{array}$ & $\begin{array}{l}\text { From these existing } \\
\text { definitions, we learn that } \\
\text { previous researchers } \\
\text { consider CT as a tool that } \\
\text { can be used to solve } \\
\text { problems. In contrast, we } \\
\text { dhe mot always need }\end{array}$ \\
Yadav et al. (2014) & $\begin{array}{l}\text { Thent process for the abstraction } \\
\text { ofoblems to hone CT. We }\end{array}$
\end{tabular}




\begin{tabular}{|c|c|c|}
\hline Denning (2009) & $\begin{array}{l}\text { Computational thinking has a long } \\
\text { history in computer science. Known in } \\
\text { the 1950s and 1960s as "algorithmic } \\
\text { thinking," it means a mental orientation } \\
\text { to formulating problems as conversions } \\
\text { of some input to output and looking for } \\
\text { algorithms to perform the conversions. } \\
\text { Today the term has been expanded to } \\
\text { include thinking with many levels of } \\
\text { abstractions, using mathematics to } \\
\text { develop algorithms, and examining how } \\
\text { well a solution scales across different } \\
\text { sizes of problems. }\end{array}$ & $\begin{array}{l}\text { try to bring CT to a wider } \\
\text { scope. Students can think } \\
\text { and learn better through } \\
\text { CT. Computers in mind as } \\
\text { a mental model to examine } \\
\text { mathematics concepts to } \\
\text { study. }\end{array}$ \\
\hline Hemmendinger (2010) & $\begin{array}{l}\text { Computational thinking is to teach them } \\
\text { how to think like an economist, a } \\
\text { physicist, an artist, and to understand } \\
\text { how to use computation to solve their } \\
\text { problems, to create, and to discover } \\
\text { new questions that can fruitfully be } \\
\text { explored. }\end{array}$ & \\
\hline
\end{tabular}

Even though Papert (1980) did not define CT explicitly in Mindstorm, he gave a hint that through CT, students can think and learn better. For instance, through CT, the linear function concept as a series of operations can be represented as a real model. Furthermore, it will become a mental model.

In traditional approaches to teaching linear function, teachers perhaps do not focus enough that linear functions such as $f(x)=2 x-3$ are algorithms. A linear function consists of a step-bystep series of instructions, namely, when someone gives a number $x$, to find the value $f(x)$, she or he must do the step-by-step computations. First, $\mathrm{x}$ is multiplied by 2 ; then, it is subtracted by 3. Students should understand that the order of the steps is significant. Doing subtraction first will not result in the same. To comprehend this algorithm idea of function and linear function was fundamental before and is much more relevant now.

To function effectively in contemporary life, people must have the skills to work collaboratively side-by-side with machines. People should develop the consciousness that they now live side-by-side with computers. Therefore, they must be able to communicate and utilize computers properly. So, modern people must be able to talk to not only other human beings but also computers. This computer culture should change mathematics teaching.

In this pandemic situation, the teaching and learning process is in a distance learning setting. The communication's between students and teachers is limited. The notion of minimally invasive education (MIE) proposed by Mitra (2000) can be an alternative way for students to learn independently with the teacher's minimum intervention. Further, MIE is a learning approach with minimum or no teacher's interventions (Mitra, 2000). Previous research about MIE also stated that applying MIE can foster mathematics achievement (Inamdar \& Kulkarni, 2007). So, it is a potential strategy to use distance learning with limited communication facilities between students and teachers.

This research takes a different notion of CT. This research reports the implementation of Papert's original idea (1980) in middle school mathematics teaching. In addition to the concept 
of CT as a problem-solving tool, it will be shown qualitatively that through $\mathrm{CT}$, students can think and learn the function concept better.

Mathematics teaching with the above understanding in mind raises the awareness of computer's roles in the present and future life. The approach could also help the students to improve their comprehension of linear function concepts. These are the two aims of the work.

\section{Methods}

This research utilized a case study approach since it fits with this research as it involves limited participants. We firstly develop a series of modules, and we examine them. However, most schools are now closed, and it is limited to conduct this research in face-to-face interaction. Then, we sent the modules through social media applications (WhatsApp.) Students were selected randomly. After that, we collect the results through the student's work (image files) sent through WhatsApp. Finally, we analysed the data through content analysis.

\section{Results and Discussion}

\section{Mathematics lesson design in an unplugged setting}

In this pandemic situation, students and teachers do the learning process in a distance mode. To facilitate student's learning with minimum intervention by the teachers, we develop several self-explained modules on a linear function. Moreover, the modules are more visual, and they do not use lengthy and wordy sentences. Furthermore, visual mathematics learning can help students imagine the topic, check the truth in their way, and increase student self-confidence (Montenegro, 2003).

To reach an effective result, we adapt the essential concept of function proposed by NCTM (2020) to represent function into a formula, table, and graphic. Thus, we focus on three modules, knowing the linear function, convert the table of a linear function to a formula, and convert the formula to a graphic. The following are the modules developed in this study.

\section{Module 1: Knowing the Linear Function}

Through this module, we try to create a mental model of a linear function. One can illustrate a linear function as a step-by-step series of operations. This model will be a mental model brought by students to understand function or other mathematics topics.

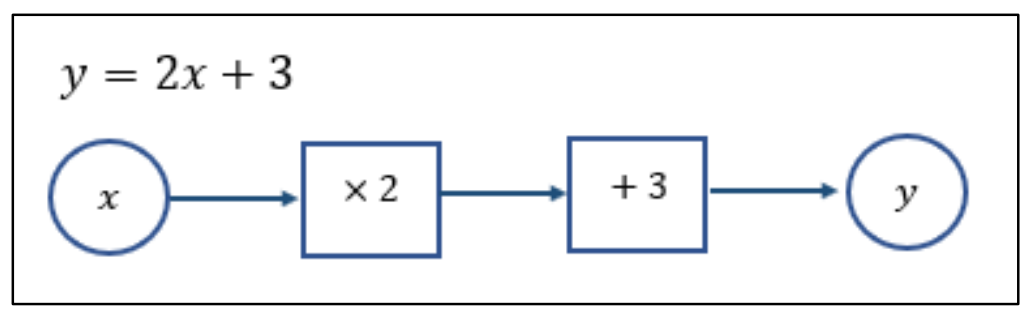

Figure 1. Sample of the task on Module 2. 
In simple terms, those step-by-step series of operations is the central part of computational thinking; it is an algorithm. Through this visualisation, we invite the students to envisage how meaningful each step of the operation. Multiplying by 2 may not be a difficult step if $\mathrm{x}$ is a small number. If we input the value of $x$ with the 9-digit specific number, students will realise that they need a computer to calculate it quickly and precisely. It has raised a student's awareness of computer ability. At the end of the modules, students input the value of $\mathrm{x}$ and try to find the gradient value $(a)$ and intercept $(b)$ according to the above steps.

\section{Module 2: Convert the Table of Linear Function to Formula}

We try to represent the straightforward conversion steps to determine the value of $a$ and $b$. Instead of using delta $\Delta$ and $y_{i}$ notation, we prefer to present it with an illustration. We try to create this module that is self-explained.

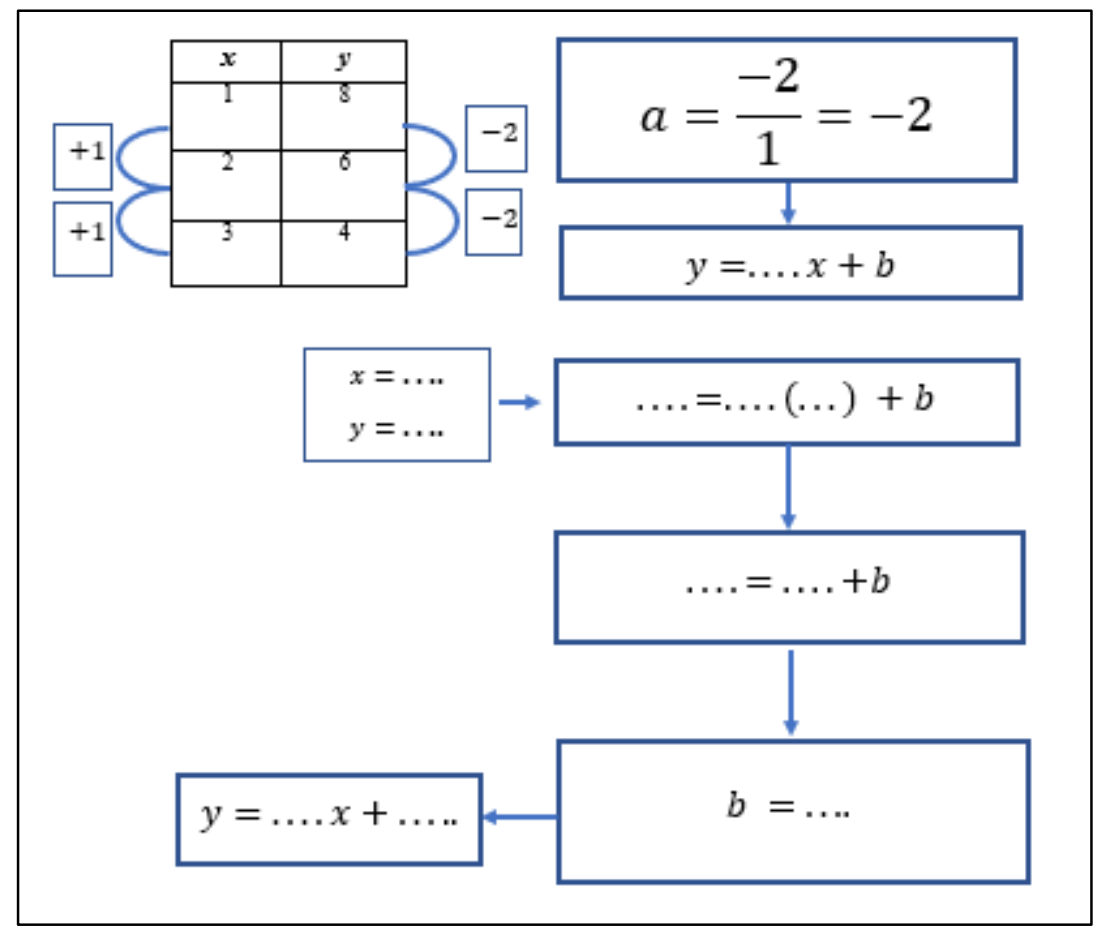

Figure 2. Sample of the task of Module 2.

Goyal (2012) said that MIE gives more opportunity for students to explore the ideas that lie in the lesson content. Students analyse that the difference between $y$ can also be a negative value. Here, we provide opportunities for students to uncover ideas about changes in the value of $y$. Again, each step of the whole algorithm is meaningful for students. Through CT, the students could comprehend the linear function concept better.

\section{Module 3: Convert Function Formula to Graphic}

This module helps students learn that each input $x$ will pair with a $y$ value as a collection of points. Then, these points are plotted on the coordinate plane. 


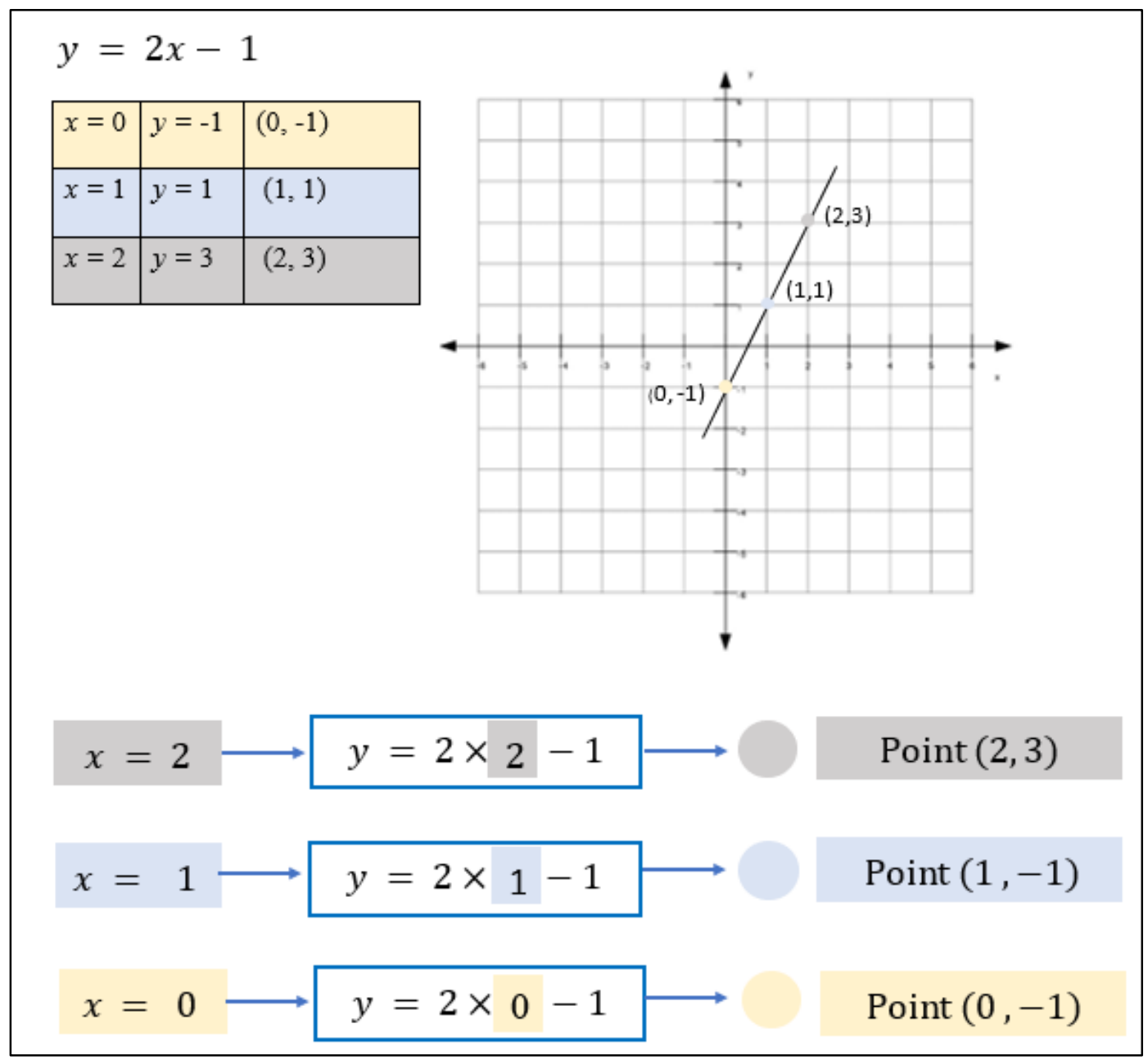

Figure 3. Sample of task on Module 3.

We provided an example of how to sketch a graphic. First, we give a complete illustration; then, we reduce the instructions gradually. Students see this process as a routine procedure suitable for computers to do. To enhance the student's understanding, we provide modules $1 \mathrm{~b}$, $2 b$, and $3 b$ with reverse instructions.

\section{Implementing mathematics learning to develop computational thinking in an unplugged setting}

The implementation of CT modules is as follows. The teacher shared the modules in pdf. via WhatsApp and asked students to copy all modules to their paper. Due to the distance learning setting applied, a teacher cannot meet the students in-person. Through mathematics instruction, we try to raise student's awareness of computer's roles in life and make students comprehend the linear function concept easier. We expect students to discover each meaning of step, such as imagine what if the input $x$ is a large number, so we need the machines help to calculate.

To confirm that students think and learn about the linear function concept better, we ask them to do regular tasks. The students do the tasks before and after doing the modules. After that, we 
arrange some interviews through WhatsApp to discuss what the students have learned. The following table summarises the student's results.

Table 2

Students Results on the Given Modules

\begin{tabular}{cccc}
\hline \multirow{2}{*}{ Lesson Instructions } & \multicolumn{3}{c}{ Students } \\
\cline { 2 - 4 } & 1 & 2 & 3 \\
\hline Pre-test & - & - & - \\
Module $1 a$ & Misconception & Misconception & Misconception \\
Module $1 b$ & Misconception & Inaccurate & Accomplished \\
Module $2 a$ & Accomplished & Accomplished & Inaccurate \\
Module $2 b$ & Inaccurate & Inaccurate & Accomplished \\
Module $3 a$ & Inaccurate & Inaccurate & - \\
Module $3 b$ & Misconception & Misconception & - \\
Post-test & Inaccurate & Inaccurate & - \\
\hline
\end{tabular}

The validity of student's works determines the above classification. In that classification, the label misconception means they do not understand the basic concept, and the label inaccurate means the student's calculation contains some errors.

From Table 2, two students accomplished Module 2a, one student accomplished Module 1b, and one student completed Module 2b. On the other modules, students could not execute yet. The following pictures show the answer of some students in Module 1a.

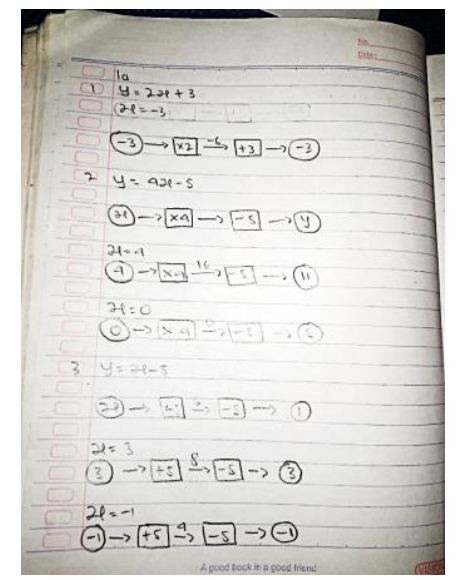

Figure 4. The answer of Student 1.

Based on the answer of Student 1 on Problem 2, it shows he could follow the instruction and fill the missing number correctly, but he missed the minus sign on the answer (it must be -5 instead of 5). Meanwhile, on problem 3, he put the incorrect number on the coefficient box. 


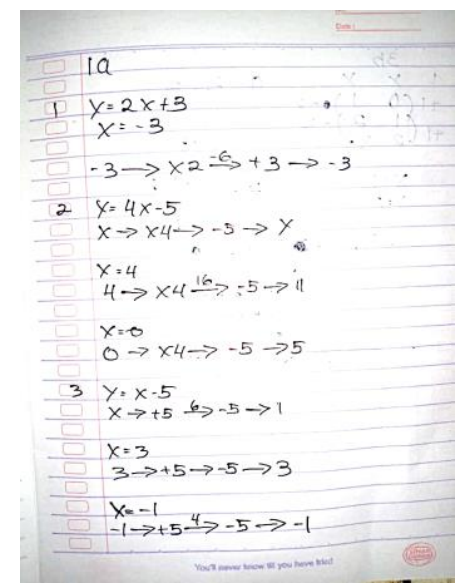

Figure 5. The answer of Student 2.

Based on Student 2's answer, he also entered the incorrect number in the coefficient box, even though he was correct in filling in the intercept box. He had a misconception about the basic linear function concept. We need to add more examples where the coefficients have been installed gradually, for instance, from $4 \mathrm{x}, 3 \mathrm{x}, 2 \mathrm{x}$, to $\mathrm{x}$.

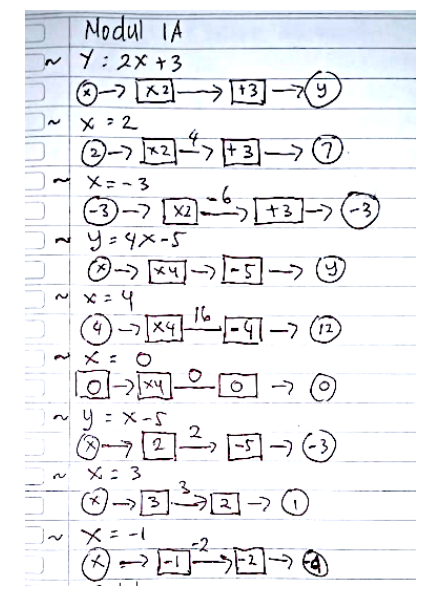

Figure 6. The answer of Student 3.

Based on Students 3's answer, it is clear that we need even more gradual examples. She did not learn from the first example well, so she put the incorrect number on the intercept box.

Besides, students could not answer the problems; the awareness of the use of information processing machines has not yet emerged. They did not realise that they do not need to compute large numbers instead of the computer. We need to add more examples on the modules, showing large number inserted and ask them to calculate. Hopefully, they will realise that the computer does the calculation of large numbers better.

From the results, it seems that it needs extra work to make students understand the instructions. The results might be different if their regular teacher carried out this lesson. This last reflection may be the vital message that our present education system is not yet ready selfteaching environment. We also cannot entirely depend on student's ability to understand instructions without the teacher's help. 


\section{Conclusion}

This study has provided insight into nurturing CT skills through an unplugged environment. The effectiveness of the modules and the implementation during pandemics need to be addressed in future research. As this study involved limited participants, one must use the results cautiously.

\section{References}

Cansu, S. K., \& Cansu, F. K. (2019). An overview of computational thinking. International Journal of Computer Science Education in Schools, 3(1), 1-11. https://doi.org/10.21585/ijcses.v3i1.53.

Denning, P. J. (2009). The profession of IT beyond computational thinking. Communications of the ACM, 52(6), 28-30. https://doi.org/10.1145/1516046.1516054.

Hemmendinger, D. (2010). A plea for modesty. ACM Inroads, 1(2), 4-7. https://doi.org/10.1145/1805724.1805725.

Inamdar, P., \& Kulkarni, A. (2007). 'Hole-In-The-Wall' computer kiosks foster mathematics achievement-A comparative study. Journal of Educational Technology \& Society, 10(2), 170-179. Retrieved from https://www.jstor.org/stable/10.2307/jeductechsoci.10.2.170.

Mitra, S. (2000). Minimally invasive education for mass computer literacy. Proceeding in Conference on Research in Distance and Adult Learning in Asia 2000, pp. 21-25. Hongkong: The Open University of Hongkong.

Montenegro, J. J. (2003). Visual Mathematics. Proceeding in 2nd International Conference on Multimedia and ICTs in Education. Spain: Badajoz.

National Council of Teachers of Mathematics (NCTM). (2018). Catalysing change in high school mathematics: initiating critical conversations. Reston, VA: NCTM.

National Council of Teachers of Mathematics (NCTM). (2020). Standards for the Preparation of Secondary Mathematics Teachers. Reston, VA: NCTM.

Papert, S. A. (1980). Mindstorms: Children, computers, and powerful ideas. New York: Basic Books.

Yadav, A., Mayfield, C., Zhou, N., Hambrusch, S., \& Korb, J. T. (2014). Computational thinking in elementary and secondary teacher education. ACM Transactions on Computing Education (TOCE), 14(1), 1-16. https://doi.org/10.1145/2576872.

Wing, J. M. (2006). Computational thinking. Communications of the ACM, 49(3), 33-35. Retrieved from http://www.cs.cmu.edu/ 15110-s13/Wing06-ct.pdf. 